\title{
Lidocaine-eluting endotracheal tube effectively attenuates intubation related airway response
}

\author{
Jing Lu ${ }^{1,2,3} \wedge$, Wenjie Tian ${ }^{3,4 \#}$, Linxian Cui ${ }^{4}$, Bing Cai ${ }^{2}$, Tingting Zhang ${ }^{5}$, Nan Huang ${ }^{6}$, Lei Lu ${ }^{5}$, Tao Zhu ${ }^{1}$ \\ ${ }^{1}$ Department of Anesthesiology, Laboratory of Anesthesia \& Critical Care Medicine, Translational Neuroscience Center, West China Hospital \\ of Sichuan University, Chengdu, China; ${ }^{2}$ Department of Anesthesiology, Sichuan Provincial People's Hospital, University of Electronic Science \\ and Technology of China, Chengdu, China; ${ }^{3}$ Chinese Academy of Sciences Sichuan Translational Medicine Research Hospital, Chengdu, China; \\ ${ }^{4}$ Department of Cardiology, Sichuan Provincial People's Hospital, University of Electronic Science and Technology of China, Chengdu, China; \\ ${ }^{5}$ School of Life Science and Engineering, Southwest Jiaotong University, Chengdu, China; ${ }^{6}$ Key Lab of Advanced Technology for Materials of \\ Education Ministry, School of Materials, Southwest Jiaotong University, Chengdu, China \\ Contributions: (I) Conception and design: J Lu, L Lu, T Zhu; (II) Administrative support: T Zhu; (III) Provision of study materials or patients: W \\ Tian, L Lu, N Huang; (IV) Collection and assembly of data: W Tian, L Cui, T Zhang; (V) Data analysis and interpretation: J Lu, W Tian, L Lu; (VI) \\ Manuscript writing: All authors; (VII) Final approval of manuscript: All authors. \\ \#These authors contributed equally to this work and are co-first authors. \\ Correspondence to: Tao Zhu. Department of Anesthesiology, Laboratory of Anesthesia \& Critical Care Medicine, Translational Neuroscience Center, \\ West China Hospital of Sichuan University, Chengdu 610041, China. Email: 739501155@qq.com; Lei Lu. School of Life Science and Engineering, \\ Southwest Jiaotong University, Chengdu 610031, China. Email: 1lu2@swjtu.edu.cn.
}

\begin{abstract}
Background: Lidocaine (LDC) is a local anesthetic widely used to relieve intubation-related airway responses. However, low drug concentration and short effective duration of LDC is inadequate to provide a satisfactory anesthetic effect on the surface of the airway. The present study sought to develop a LDCdelivery endotracheal tube (ETT) to achieve high local drug concentration and sustained drug release with the aim of attenuating an intubation-related airway response.
\end{abstract}

Methods: ETTs and polyvinyl chloride (PVC) discs were coated with different molecular weight (MW) poly lactic-co-glycolic acid (PLGA: 50/50; MW: 3,000, 6,000, and 10,000) loaded with LDC by airbrush spray. The morphology of LDC-eluting coatings was analyzed using scanning electron microscopy. In vitro drug release was determined by ultraviolet spectrophotometer. An in vivo study was performed to investigate the differences in plasma LDC concentration, intubation tolerance, and tracheal tissue injury in rabbits undergoing intubation of blank, LDC-spray, or LDC-coated ETTs.

Results: Approximate $5 \mathrm{mg} / \mathrm{cm}^{2}$ coatings (containing $2.5 \mathrm{mg} / \mathrm{cm}^{2} \mathrm{LDC}$ ) were deposited onto the PVC discs and ETTs. While even distribution and smooth surfaces were generated in PLGA3000 + LDC and PLGA6000 + LDC coatings, PLGA10000 + LDC formed uneven and gullied coatings. Burst release within the first $4 \mathrm{~h}$ and sustained release for at least 5 days was achieved in vitro in PLGA + LDC coatings and the in vivo study demonstrated higher plasma LDC concentration and longer drug release duration in LDC-coated ETTs compared with LDC-spray. LDC-coated ETTs significantly improved intubation tolerance in rabbits, as measured by less general anesthetic consumption and longer tube tolerance duration in contrast to blank ETTs with or without LDC spray. Histology assessment showed less mucosal edema area in the PLGA3000 + LDC and PLGA6000 + LDC groups compared to the control, LDC-spray, and PLGA10000 + LDC groups. Among the different MW PLGAs, PLGA6000 presented optimal morphological characteristics, drug release, and anesthetic effect.

Conclusions: ETTs coated with PLGA + LDC effectively attenuate an intubation-related airway response

^ ORCID: Wenjie Tian, 0000-0002-4328-0255; Jing Lu, 0000-0003-4468-7134. 
via increasing local drug concentration and extending drug action duration, which demonstrates a potential therapeutic benefit for patients undergoing intubation.

Keywords: Lidocaine; endotracheal tube (ETT); local anesthesia; drug release; poly lactic-co-glycolic acid (PLGA)

Submitted Mar 16, 2021. Accepted for publication May 21, 2021.

doi: $10.21037 / \mathrm{atm}-21-1930$

View this article at: http://dx.doi.org/10.21037/atm-21-1930

\section{Introduction}

Endotracheal intubation is a widely used medical technique to maintain an open airway, prevent suffocation, and facilitate ventilation in the operating room and intensive care unit. During the ongoing epidemic of coronavirus disease 2019 (COVID-19), many critically ill patients with COVID-19 survived acute respiratory failure due to the use of endotracheal intubation and mechanical ventilation $(1,2)$. However, endotracheal intubation-related mechanical stimulation is clinically common and associated with various airway complications, such as severe coughing, laryngeal injury and postoperative sore throat (POST) (3-5). The intubation-induced airway response is prone to increase the risk of adverse cardiovascular events including arrhythmias, hypertension, myocardial ischemia, and intracranial pressure elevation $(4,6,7)$. Further, for patients experiencing major procedures or craniocerebral operations, dramatic hemodynamic fluctuations due to the intolerance of endotracheal intubation may result in life-threatening complications such as incision bleeding and cerebrovascular accidents (8).

Common clinical approaches to attenuate intubationinduced airway and hemodynamic responses include shortacting opioids, anti-arrhythmia agents, and intravenous or topical anesthetic agents $(9,10)$. Among these, topical lidocaine (LDC) has been applied for decades by means of intratracheal spray, oxygen atomization, intracuff filling, or gel lubrication due to the advantage of its simple operation, direct absorption, and rapid anesthetic effect (3,9-14). However, the topical use of LDC does not provide a longterm anesthetic effect due to the relatively low doses used and short effective anesthetic duration ( 1 to $2 \mathrm{~h}$, or less) $(3,7,9,15)$. To conquer these limitations, a reasonable option is to use a sustained drug release technique to locally deliver anesthetic agent, which allows for an extended effective duration, a higher local drug concentration, and lower adverse effects. Recent studies showed that the sustained release of corticosteroids or antimicrobials from surface coatings, including electrospinning, hydrogel, and dip coatings, on endotracheal tubes (ETTs) is feasible and effective in reducing inflammatory reactions and preventing ventilator-related infection (16-18). Therefore, surface coating techniques may also be applicable to local LDC delivery for enhancing the local anesthetic effect.

Drug-eluting stents have become one of the most successful implantable biomedical devices over the last two decades and have greatly transformed the field of interventional cardiology $(19,20)$. DES are comprised of a polymer coating that controls the release of an antiantiproliferative drug, and one of the most used polymer biomaterials is poly lactic-co-glycolic acid (PLGA), which can be fully degraded and metabolized in vivo. As an FDA approved polymer, PLGA has been extensively applied in controlled drug release techniques, due to its biocompatibility, biodegradability, a wide range of degradation rates, and tunable mechanical properties. The PLGA-based drug delivery systems, including nanoparticles and coatings, have been proven to be effective and safe in the airway and some are available on the market $(21,22)$.

Herein, we developed a simple LDC-eluting coating technique for ETT to locally deliver LDC on the tracheal surface and eventually attenuate an intubation-related airway response (Figure 1A,B). Specifically, inspired by DES techniques, LDC was loaded on the surface of a tracheal tube via PLGA airbrush spray coatings (Figure 1C). Compared to other reported ETT coating techniques, the evaporation of spray coating is faster, which reduces the impact on the substrate from dip coatings where the tube needs to be immersed in solvent (18), and can easily prepare a thin, uniform, and transparent coating. At the same time, hydrogel (17) and electrospinning (16) ETT coatings are thicker $(0.17-0.2 \mathrm{~mm})$, which may limit their application in small diameter ETTs, such as size 2.5: inner diameter $=2.5 \mathrm{~mm}$, and outer diameter $=3.3 \mathrm{~mm}$. 

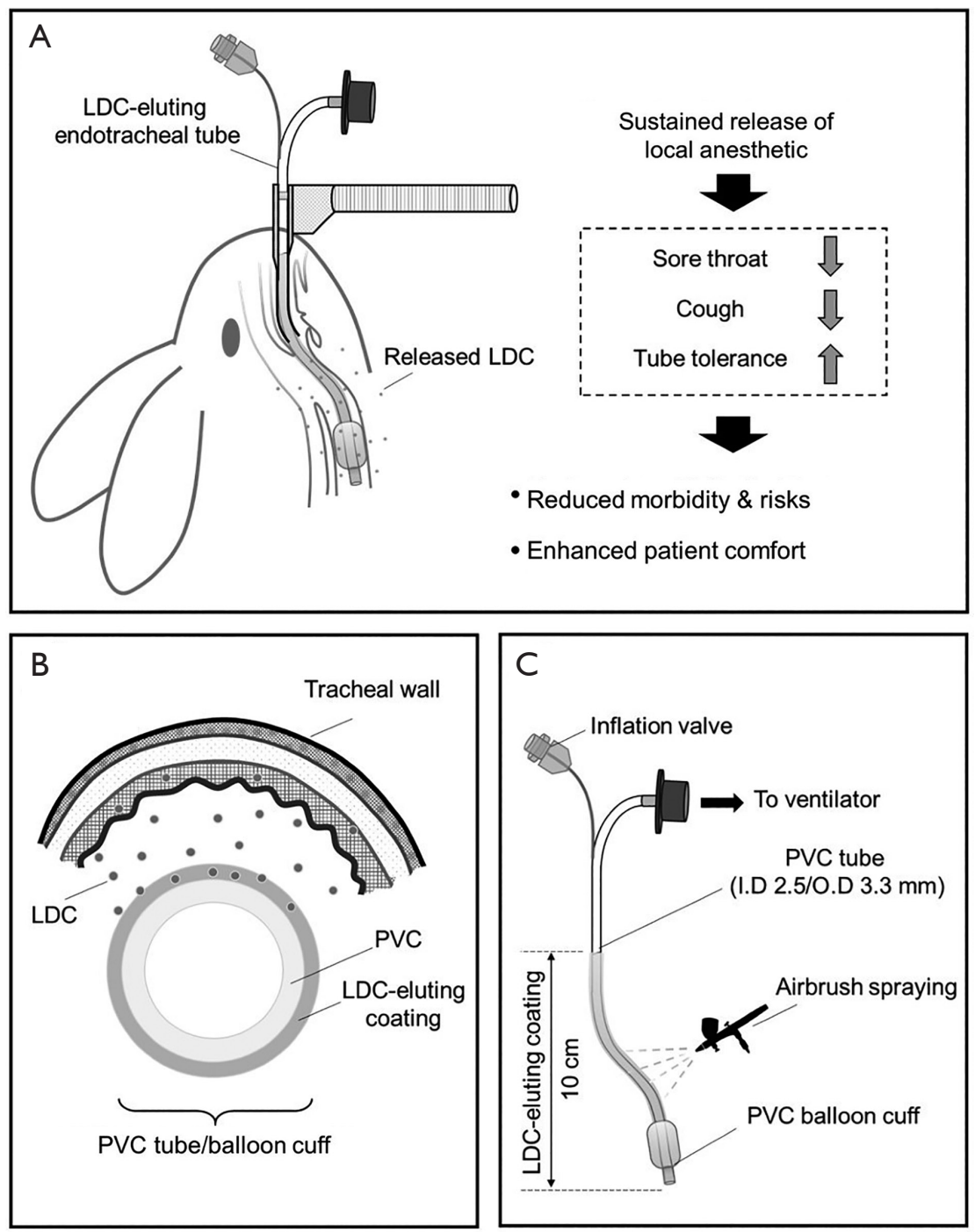

Figure 1 Schematic of LDL-eluting endotracheal tube. (A) schematic illustration for LDC-eluting endotracheal intubation in a rabbit model; (B) cross-section of sustained release of LDC from LDC-eluting coating to tracheal wall; (C) structure and fabrication of LDCeluting ETT. LDC, lidocaine; ETT, endotracheal tube.

As the PLGA degradation rate and drug release are related to its molecular weight $(\mathrm{MW})(22,23)$, we selected three low MW PLGA (50:50; MW: 3,000, 6,000, and $10,000)$ to assess the influence of $M W$ on drug release. The plasma LDC concentration at different time intervals, the anesthesia efficacy of LDC-eluting coating, and the tracheal tissue damage were then evaluated in a rabbit intubation model. We present the following article in accordance with the ARRIVE reporting checklist (available at http://dx.doi. org/10.21037/atm-21-1930).

\section{Methods}

\section{Materials}

Lidocaine powder ( $\geq 99 \%$ purity) and PLGA (50:50, MW: 3,000, 6,000, 10,000) were purchased from Aladdin (Shanghai, China), and the Daigang Bio-technology Co., Ltd. (Jinan, Shandong, China), respectively, and dichloromethane (DCM) was purchased from Chron Chemicals Co., Ltd (Chengdu, Sichuan, China). ETTs that fit the trachea of a rabbit (size 2.5: inner diameter $=2.5 \mathrm{~mm}$, 
outer diameter $=3.3 \mathrm{~mm}$ ) were purchased from the Henan Tuoren Kingtaek Medical Device Co., Ltd (Xinxiang, Henan, China), and medical grade polyvinyl chloride (PVC, widely used polymers for fabricating ETTs) was purchased from the Dongguan Sunyo Plastic Co., Ltd., (Dongguan, Guangdong, China) and cut into discs (diameter $=14 \mathrm{~mm}$ ).

\section{Preparation of LDC-eluting coatings}

LDC-eluting coatings were performed using an airbrush paint sprayer (U Star R-102 + 201, China). Both PLGA (50:50, MW: 3,000, 6,000, 10,000) and LDC were dissolved in DCM at a concentration of $10 \mathrm{wt} \%$ and the PLGA control was $10 \mathrm{wt} \%$ PLGA in DCM alone. The PVC discs were carefully cleaned using an ultrasonic cleaning method with ethanol and deionized water in sequence (three times for $5 \mathrm{~min}$ ) and dried by nitrogen blowing. PLGA/LDC solutions, PLGA solutions, or DCM were sprayed onto both sides of the cleaned PVC discs and ETTs $(10 \mathrm{~cm}$ from the top, Figure 1C), with a fixed $15 \mathrm{~cm}$ distance from the tube surface and varying time. The discs and tubes were rotated during the spraying process and the coatings were dried by nitrogen blowing and vacuumed before use. For preparing LDC-eluting ETTs, an additional layer of coating was applied to ensure the desired dose if the weight of the first layer was insufficient.

\section{Characterization of LDC-eluting coatings}

The coating thickness was measured by a digital micrometer (Sanliang 211, Dongguan, Guangdong, China) and the coating weight was measured by electronic scales (BT125D, Satorius, Germany). The water contact angle of each coating at room temperature was measured using a Drop Shape Analysis System (DSA100, GmbH Hamburg, Germany) and five $\mu \mathrm{L}$ of deionized water was used as the probing liquid $(\mathrm{n} \geq 6)$. The chemical composition of the LDC-eluting coating was analyzed by the reflection absorption-Fourier transform infrared spectroscopy (RAFTIR, Nicolet model 5700 instrument, USA) of Au substrates deposited with LDC, polymers, and LDC-eluting coatings.

\section{Morphology of LDC-eluting coatings}

Samples were photographed by digital camera, then the morphology of LDC-eluting coatings on ETTs was analyzed by scanning electron microscopy (SEM, Quanta
200 and Inspect F50, FEI, Netherlands) after being washed with deionized water and dried by nitrogen blowing.

\section{In vitro drug release from $L D C$-eluting coatings}

The in vitro LDC release study was performed by incubating LDC-coated PVC discs in $20 \mathrm{~mL}$ PBS buffer $\left(\mathrm{pH} \mathrm{7.4)}\right.$, at $37^{\circ} \mathrm{C}$. At appropriate intervals, the supernatants of the samples were collected and centrifuged $(6,000 \mathrm{rpm}$, $15 \mathrm{~min}$, at room temperature) to remove insoluble substance. The amount of released LDC was measured by $\mathrm{UV}-\mathrm{Vis}$ at $263 \mathrm{~nm}(\mathrm{n} \geq 3)$ and the standard curve was made by LDC solutions measured in the same way. Coatings without LDC were used as blank.

\section{Experimental animals}

This study was approved by the West China Hospital of Sichuan University Biomedical Research Ethics Committee and animals were treated in accordance with the Guide for the Care and Use of Laboratory Animal of the US National Institutes of Health (NIH). Twelve-week-old, healthy female or male New Zealand White (NZW) rabbits (Dasuo experimental animal center, Chengdu, China) weighing $\sim 2.5 \mathrm{~kg}$ were used. Rabbits weighing less than $2.2 \mathrm{~kg}$ or over $2.8 \mathrm{~kg}$, or in a state of pregnancy were excluded. Rabbits were acclimatized for a period of 7 days prior to the procedure with adequate food supply. Ultraviolet disinfection was applied on all tubes with coatings before intubation. Animal experiment was performed according to a protocol prepared before the study.

\section{Measurement of physiological variables}

Prior to anesthesia induction, oxygen was provided by face mask at $3 \mathrm{~L} / \mathrm{min}$ for $5 \mathrm{~min}$, an over-the-needle catheter (24 G) was placed percutaneously into a marginal ear vein, and a T-connection was attached. A further over-theneedle catheter $(20 \mathrm{G})$ was placed percutaneously into the central auricular artery and connected to a T-connection (Figure $2 A$ and $A$-i). The $20 \mathrm{G}$ in the auricular artery was connected to a calibrated pressure transducer (zeroed level with the thoracic inlet) to obtain arterial systolic and diastolic blood pressure (SBP and DBP). After intravenous access was achieved, animals were anesthetized by intravenous propofol (bolus intravenous injection $10 \mathrm{mg} / \mathrm{kg}$ for anesthesia induction and continuous infusion $0.5 \mathrm{mg} / \mathrm{kg} \cdot \mathrm{min}$ for anesthesia maintenance). Physiological 
variables including heart rate, respiratory rate, SBP, DBP, arterial oxygen saturation $\left(\mathrm{SaO}_{2}\right)$, and end tidal $\mathrm{CO}_{2}$ concentration $\left(\mathrm{EtCO}_{2}\right)$ were monitored and recorded every 5 min after intubation.

\section{Endotracheal intubation}

Rabbits were randomly assigned to one of five groups to undergo endotracheal intubation and the operator was blinded to the type of ETTs (animal number in each group is over 5 to ensure the statistical significance): (I) control ( $\mathrm{n} \geq 5)$, intubated with blank PVC tracheal tube; (II) LDC spay $(\mathrm{n} \geq 5)$, intubated with blank PVC tracheal tube after spraying $0.5 \mathrm{~mL} 2 \% \mathrm{LDC}$ (total $10 \mathrm{mg}$ ) at the site of laryngeal; (III) PLGA3000 + LDC-eluting ( $\geq 5$ ); (IV) PLGA6000 + LDC-eluting ( $\geq 5)$; (V) PLGA10000 + LDCeluting ( $\mathrm{n} \geq 5$ ). Rabbits from group (III) to (V) were intubated with LDC-eluting ETTs coated with corresponding PLGA MW, with the insertion depth of ETTs determined by measurement from the incisors to the thoracic inlet. After anesthesia induction, trans-oral endotracheal intubation was performed in the following way (Figure $2 A$ and $A-i$ ): a guide wire (0.035-inch, $60 \mathrm{~cm}$, Braun Medical, Germany) was introduced into the tracheal tube lumen and remained protruded $50 \mathrm{~mm}$ from the tip of the tube. With the guidance of pediatric laryngoscopy, the guide wire was placed into the trachea and the tube advanced over the wire. As the tube was properly placed, the guide wire was retrieved and the tube fixed with tape. An anesthesia circuit was connected to verify the placement of the ETT and ensure ventilation for both sides of the lungs by observing $\mathrm{EtCO}_{2}$. Anesthesia was maintained with propofol according to the above-mentioned dose, and a supplemental bolus of propofol (7-10 mg each time) was intravenously injected when animals showed signs of severe cough or significant limb movements. Supplemental propofol was repeatedly administered if necessary. Intubation was successfully performed in all rabbits within an average of $4 \pm 2 \mathrm{~min}$ from anesthesia induction and ventilatory support was obtained from the animal ventilator (Dräger, Germany) during general anesthesia (respiratory rate: $49 \pm 7$ per $\mathrm{min}$ ).

\section{Plasma LDC concentration measurement}

Over the course of $5 \mathrm{~h}$ following intubation, a $1.0-\mathrm{mL}$ blood sample was collected at each one-hour interval via an over-the-needle catheter to measure the plasma LDC concentration. Plasma was separated by centrifugation at $2,000 \mathrm{~g}$ for $15 \mathrm{~min}$ at $4{ }^{\circ} \mathrm{C}$ and stored at $-80{ }^{\circ} \mathrm{C}$. The determination of LDC was performed with minor modifications using HPLC-MS/MS (Agilent 1260-6460, USA), and ropivacaine water solution $(100 \mathrm{ng} / \mathrm{mL})$ was used as an internal standard solution (IS). Plasma $(5 \mu \mathrm{L})$ was diluted with $45 \mu \mathrm{L}$ deionized water and $5 \mu \mathrm{L}$ IS, then mixed with $150 \mu \mathrm{L}$ acetonitrile and vortexed for $30 \mathrm{~s}$, and a supernatant sample $(100 \mu \mathrm{L})$ was isolated by centrifugation at $3,000 \mathrm{rpm}$ for $10 \mathrm{~min}$ at $4{ }^{\circ} \mathrm{C}$.

Liquid chromatography analyses of LDC and the internal standards were performed on an Agilent Hillc C18 column $(3.0 \times 100 \mathrm{~mm}, 3.5 \mu \mathrm{m}$, Agilent, USA). The mobile phase consisted of $0.1 \%$ formic acid water solution: acetonitrile, 50:50 (v/v). An aliquot of a $1 \mu \mathrm{L}$ supernatant sample was injected at a flow rate of $0.3 \mathrm{~mL} / \mathrm{min}$ to give a total chromatographic run time of $6 \mathrm{~min}$, and the column temperature was $30{ }^{\circ} \mathrm{C}$. Multiple-reaction monitoring (MRM) used the transitions of the protonated molecules at $\mathrm{m} / \mathrm{z} 235.1$ to $\mathrm{m} / \mathrm{z} 86.1$ for LDC, and the standard curve was made by LDC water solutions $\left(\mathrm{R}^{2}>0.9976\right)$.

\section{Efficacy and safety evaluation of LDC-eluting ETT}

During the $5 \mathrm{~h}$ period of anesthesia, supplemental propofol was administered by the above-mentioned protocol to ensure sufficient anesthesia and the total consumption of supplemental propofol within $5 \mathrm{~h}$ was recorded. After anesthesia, propofol infusion was stopped and the rabbits were allowed to gradually awaken. With the ETTs remaining in place, the rabbits were observed for signs of tube intolerance such as cough, head shaking, or pulling the tube, and upon occurrence, the tube was removed and the duration from being awake to tube removal was recorded. Among the groups, the variability in tube tolerance would result in different propofol consumption and a different duration for the tube to remain. Therefore, we set up two parameters to evaluate the efficacy of LDC-eluting ETTs: (I) the total consumption of supplemental propofol within $5 \mathrm{~h}$; (II) post-anesthesia tube tolerance duration, which was defined as the duration from being awake to tube removal.

Subsequently, rabbits were either euthanized for histology assessment or followed-up for 7 days for safety evaluation to determine whether dyskinesia, ataxia, restlessness, and/or death occurred.

\section{Histology assessment for tissue damage}

After $5 \mathrm{~h}$ of intubation, animals were euthanized by an 

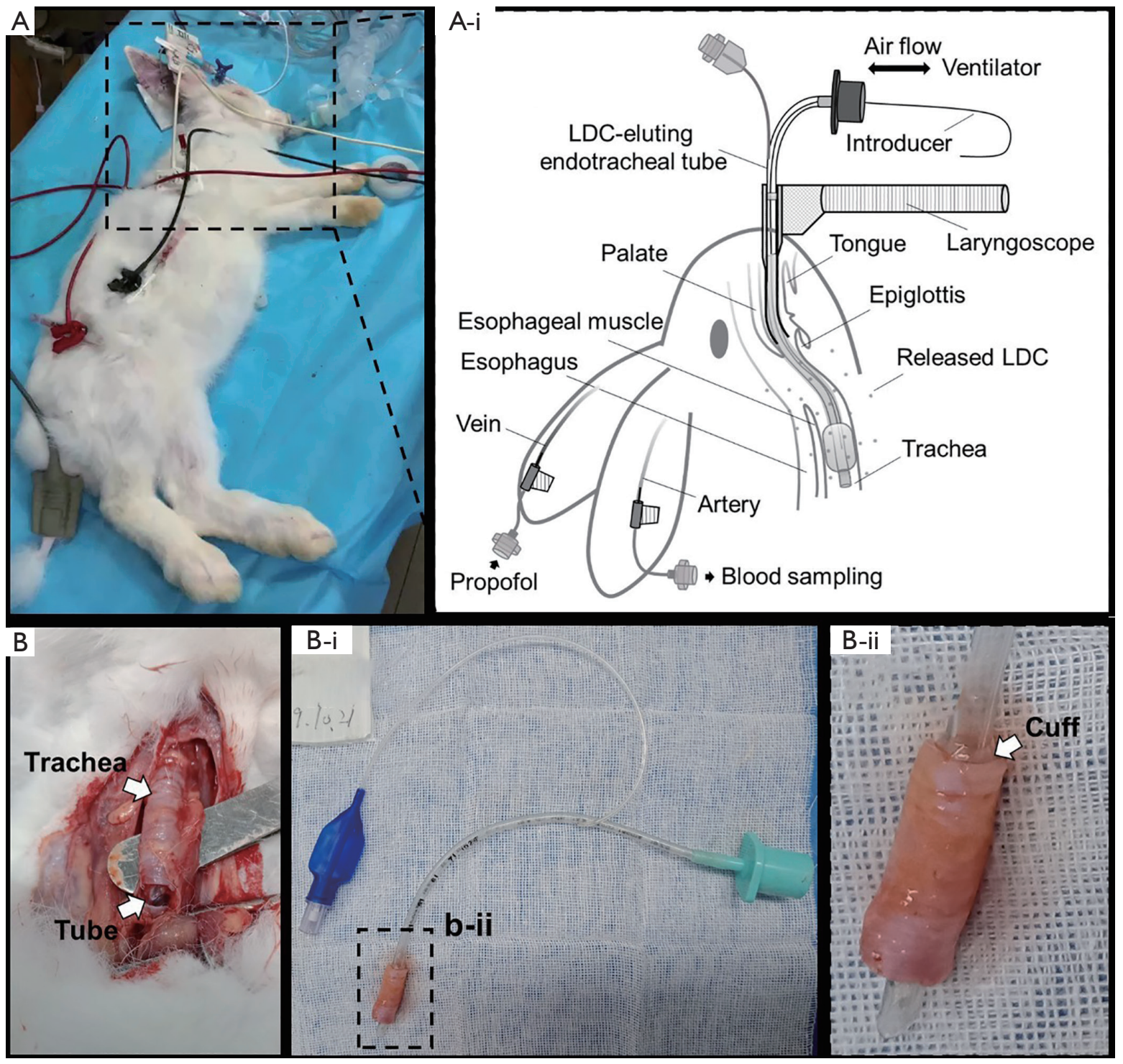

Figure 2 Schematic of the rabbit model used for the intubation test. Photo of intubated rabbit (A) and method (A-i). Trachea tissue attached to the tube cuff was harvested after experiment (B).

overdose of propofol $(40 \mathrm{mg})(\mathrm{n} \geq 3)$ for each group, and the tracheal tissue close to the cuff carefully excised (Figure $2 B$, $B-i, B-i i)$. The harvested tissues were fixed in $4 \%$ paraformaldehyde for 3 days, then embedded in paraffin and cut into $5 \mu \mathrm{m}$ sections. Hematoxylin and eosin (HE) staining of paraffin sections was performed for histological analysis and the sections were analyzed using Pannoramic MIDI FL digital slide scanner (3DHISTECH Ltd., Hungary) with CaseViewer software (3DHISTECH Ltd., Hungary). The mucosal thickness and cross-section area of tracheal mucosal edema were measured in four areas of each section, and the average mucosal thickness and edema area were calculated $(\mathrm{n} \geq 6)$.

\section{Statistical analysis}

GraphPad Prism (Version 8.0.2, GraphPad Software Inc.) was used for data analysis. All data were presented as mean \pm standard error of the mean (SEM). Data were not included if the animals were dead due to the intubation 
into esophagus. Group comparisons were performed using one-way ANOVA followed by Sidak post-hoc testing and a $\mathrm{P}$ value of less than 0.05 was considered statistically significant.

\section{Results}

\section{Characterization and morphology of LDC-eluting ETT}

As shown in Figure 3A, transparent LDC-eluting coatings were deposited onto the PVC discs by airbrush spraying with different times. The coating weight could be controlled by the spraying time, and $\sim 5 \mathrm{mg} / \mathrm{cm}^{2}$ coatings $\left(\sim 2.5 \mathrm{mg} / \mathrm{cm}^{2}\right.$ LDC) could be obtained by 10s (PLGA3000 + LDC and PLGA10000 + LDC) or 15s (PLGA6000 + LDC) spraying, which made the theoretical amount of LDC on each tube $\sim 25.9 \mathrm{mg}$ (coating area was estimated as $0.33 \mathrm{~cm} \times 3.14 \times$ $\left.10 \mathrm{~cm}=10.36 \mathrm{~cm}^{2}\right)$. These spraying times were selected for the tube preparation (dashed line boxes in Figure $3 A$ and $B$ ). The PLGA6000 + LDC sample showed the smoothest and most evenly distributed coating, compared with PLGA3000 + LDC and PLGA10000 + LDC (Figure 3C). The measured dose of LDC per area and loading dose on all tubes was $2.45-2.58 \mathrm{mg} / \mathrm{cm}^{2}$ and $25.32-26.52 \mathrm{mg}$, respectively, which had no significance compared with coatings on PVC discs (Table S1). Although the coating weights were similar (Figure 3D), the coating thickness in PLGA3000 + LDC was significantly greater than PLGA6000 + LDC and PLGA10000 + LDC $(\mathrm{P}<0.01$ and $\mathrm{P}<0.001$ respectively, Figure 3E).

Chemical analyses of the drug-eluting coatings, pure polymers, and LDC were performed by RA-FTIR spectroscopy over a range of 4,000 to $500 \mathrm{~cm}^{-1}$ (Figure $3 F$ ). The drug-eluting coatings showed similar spectroscopic profiles compared to pure PLGA polymers (such as the characteristic $\mathrm{O}-\mathrm{C}=\mathrm{O}$ pick of PLGA at $\sim 1,780 \mathrm{~cm}^{-1}$ ), although with some minor differences. The emerged peaks at 3,300 and $\sim 1,500 \mathrm{~cm}^{-1}$ in all coatings may be attributed to the $\mathrm{N}-\mathrm{H}$ stretching and $\mathrm{N}-\mathrm{H}$ bending (Amide II) of LDC, respectively. The increasing absorption of each coating at $\sim 2,850$ and $\sim 1,650 \mathrm{~cm}^{-1}$ corresponded to $(\mathrm{N}) \mathrm{C}-\mathrm{H}$ stretching and $\mathrm{C}=\mathrm{O}$ bonds (Amide I) of LDC, respectively (24) and the characteristic peaks shared by coatings and LDC indicated the presence of LDC in the eluting coatings.

The water contact angle of PVC and each coating are shown in Figure $\mathrm{S} 1$. The significant decrease $(\mathrm{P}<0.01)$ in the water contact angles of the LDC-eluting samples indicated the successful deposition of PLGA and LDC, which are more hydrophilic than the PVC surface.

The SEM morphology of uncoated PVC and LDCeluting coating ETTs are shown in Figure 4A,B,C,D. While PLGA3000 + LDC and PLGA6000 + LDC coatings demonstrated even distribution and smooth surfaces (Figure 4B,C), PLGA10000 + LDC showed uneven and gullied formation, which may be attributed to the higher MW of PLGA10000 polymer that provided a higher cohesive force of polymer chains (Figure 4D). The effect of DCM spraying on PVC tube was evaluated, and as shown in Figure S2, DCM has little influence on the PVC, although minor swelling could be observed under SEM.

\section{In vitro release of $L D C$ from coatings}

The drug release profile from LDC-eluting coatings are shown in Figure 5. Initial burst release occurred within the first $4 \mathrm{~h}$, which may be due to the diffusion of LDC on the coating surface. Higher MW PLGA was associated with a lower release rate: $56.0 \%$ and $46.6 \%$ LDC were released within the first $4 \mathrm{~h}$ from the PLGA3000 + LDC group and PLGA6000 + LDC group, respectively. In contrast, only $20.3 \%$ LDC was released from the coating of the PLGA10000 + LDC group, which was significantly lower than the PLGA3000 + LDC and PLGA6000 + LDC groups at $4 \mathrm{~h}(\mathrm{P}<0.001$ and $\mathrm{P}<0.05$, respectively Figure $5 A)$. As illustrated in Figure 5B, all LDC-coated groups achieved a sustained release for at least 5 days, while the higher MW of PLGA resulted in a significantly lower release rate $($ PLGA10000 + LDC $<$ PLGA6000 + LDC $<$ PLGA3000 + LDC). Approximately $48 \%$, 56\%, and $68 \%$ of the loaded LDC was released over 5 days of incubation from PLGA10000 + LDC, PLGA6000 + LDC, and PLGA3000 + LDC, respectively. Thus, the release rate and desired dose of LDC during intubation could be adjusted by controlling PLGA MW, which determines both the diffusion rate of loaded drug and degradation rate of the polymer.

\section{In vivo drug release}

LDC plasma concentration levels were measured at different time points post intubation (Figure 6). The peak plasma concentration of LDC in all drug-eluting groups was less than $1,400 \mathrm{ng} / \mathrm{mL}$, which is much lower than the peak LDC plasma concentration by conventional intravenous administration [IV; e.g., 2,200 $\pm 100 \mathrm{ng} / \mathrm{mL}$ (15)]. The LDC plasma concentration in the LDC spray group dropped 
A

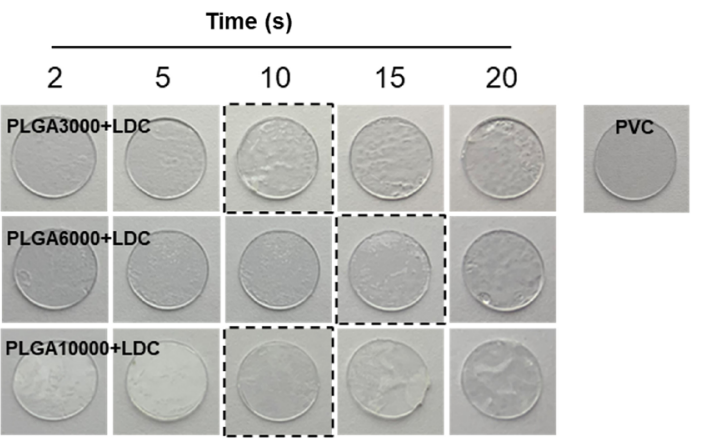

B

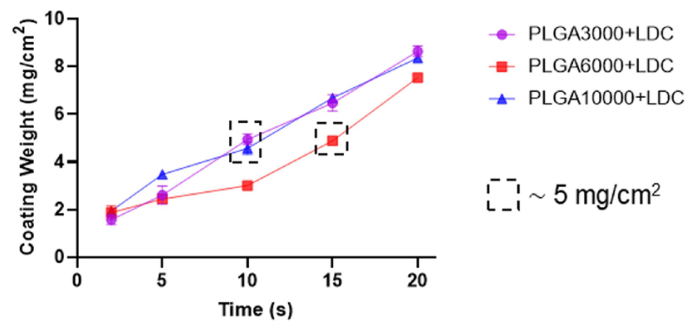

C
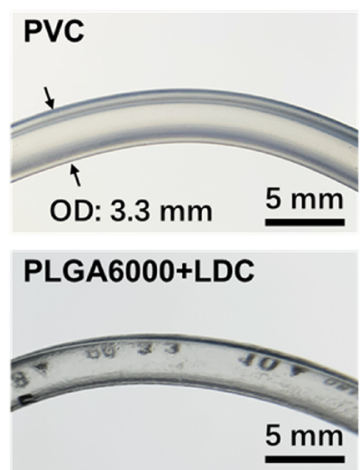

D

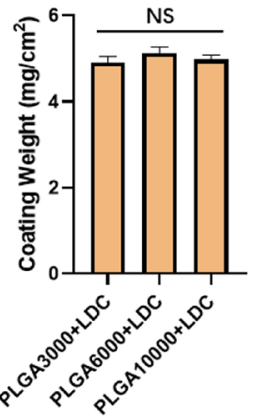

PLGA3000+LDC
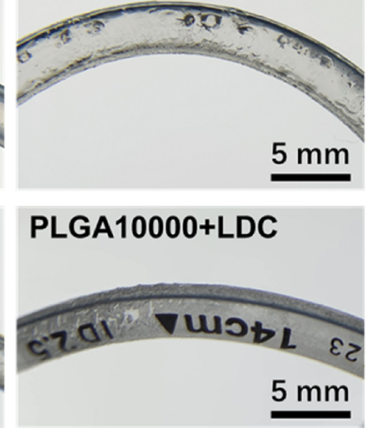

E

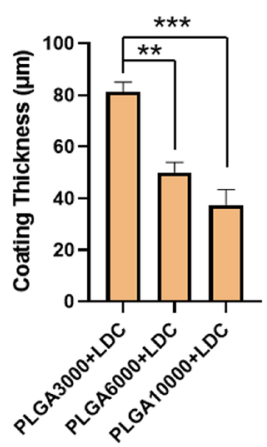

$\mathrm{F}-\mathrm{i}$

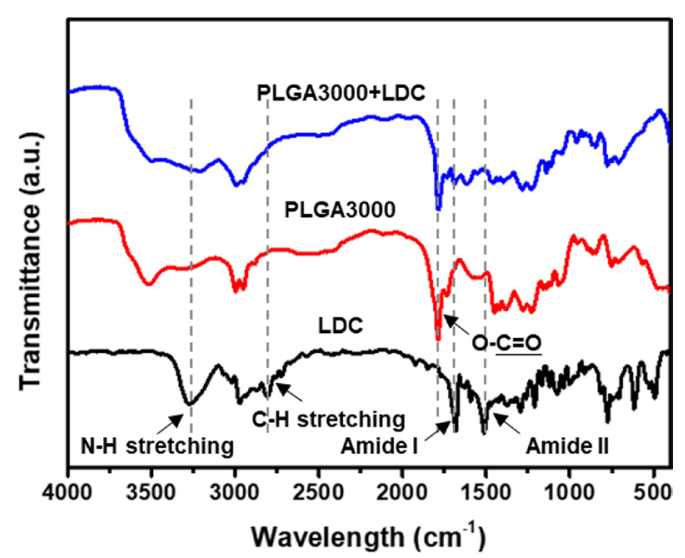

F-ii

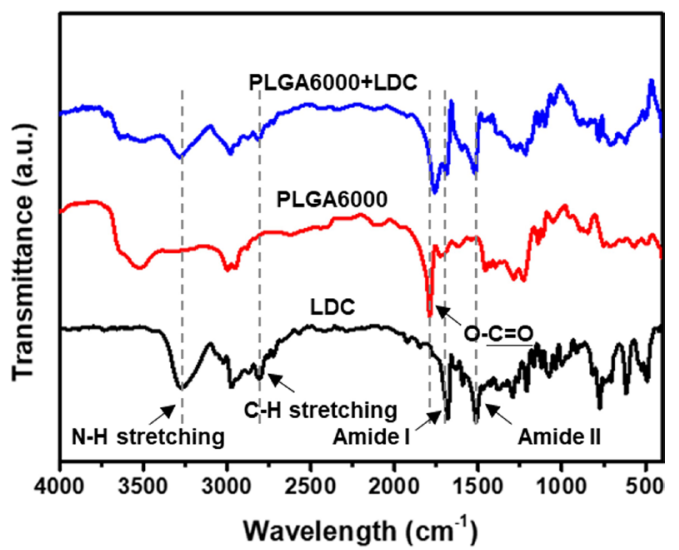

F-iii

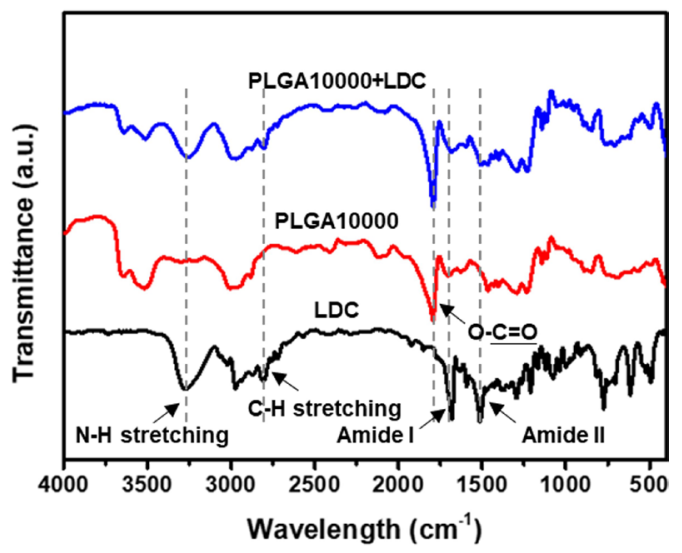

Figure 3 Characterization of LDC-eluting coatings. The images of LDC-eluting coatings prepared by airbrush spray with different times (A). The coating weight was spraying time-dependent, where $10 \mathrm{~s}$ spraying of PLGA3000 + LDC or PLGA10000 + LDC, and $15 \mathrm{~s}$ spraying of PLGA6000 + LDC obtained similar weight of coatings $\left(\sim 5 \mathrm{mg} / \mathrm{cm}^{2}, \mathrm{P}>0.05\right.$, non-significance) (B). The images of LDC-eluting ETTs (C). The measured coating weight (D) and coating thickness (E) on ETTs. RA-FTIR spectra of LDC-eluting coatings (F-i: PLGA3000 + LDC; F-ii: PLGA6000 + LDC; F-iii: PLGA10000 + LDC). **, $\mathrm{P}<0.01$; ***, $\mathrm{P}<0.001$ ( $\mathrm{n} \geq 5)$. LDC, lidocaine; PLGA, poly lactic-co-glycolic acid. 


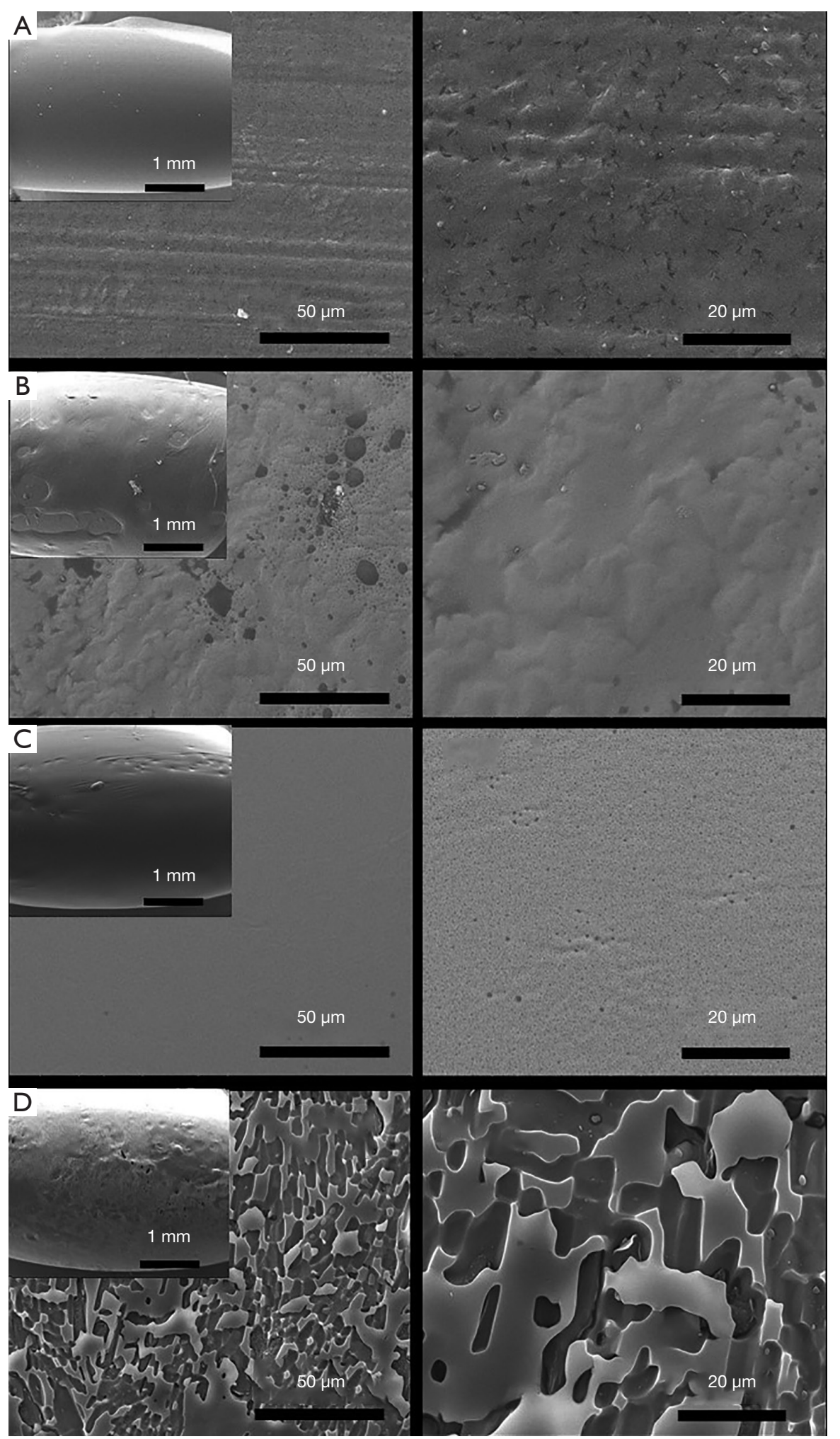

Figure 4 SEM morphology of endotracheal tubes. Uncoated PVC tube (A) and LDC-eluting coatings: PLGA3000 + LDC (B), PLGA6000 + LDC (C) and PLGA10000 + LDC (D). SEM, scanning electron microscopy; PVC, polyvinyl chloride; PLGA, poly lactic-co-glycolic acid; LDC, lidocaine. 


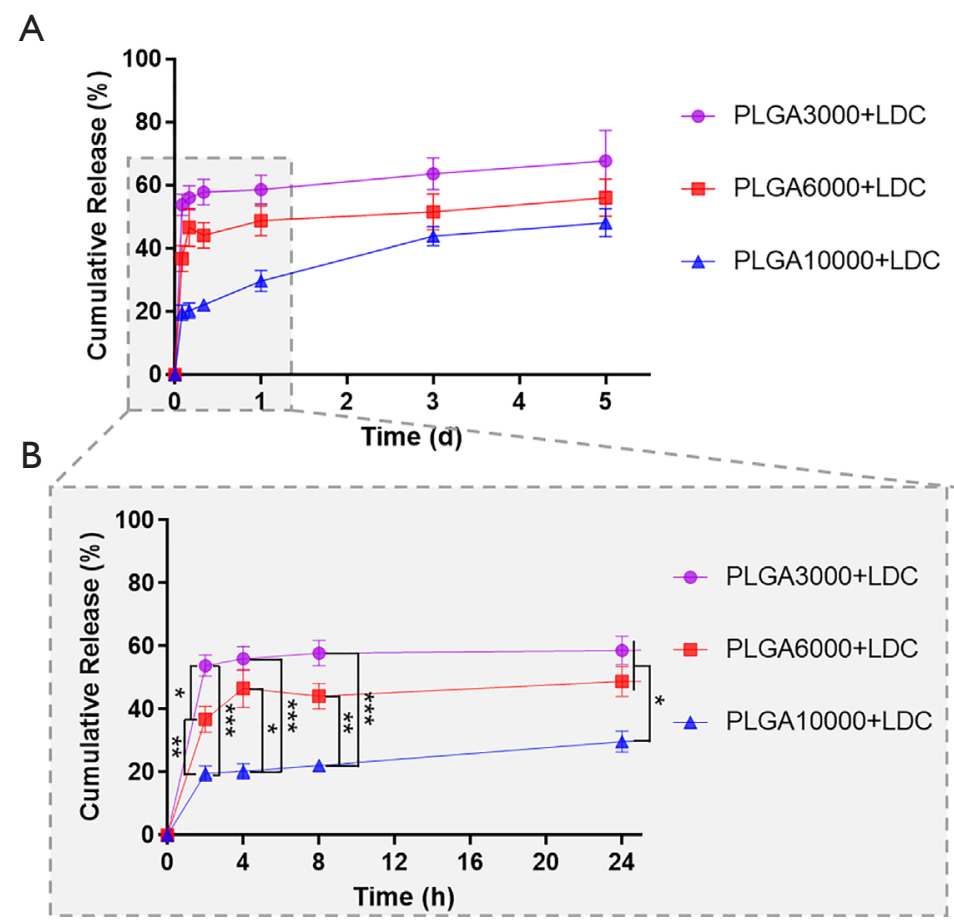

Figure 5 In vitro LDC release from coating. The cumulative release of LDC from PLGA3000 + LDC, PLGA6000 + LDC, and PLGA10000 + LDC in the first 5 days and 24 h. *, $\mathrm{P}<0.05 ;{ }^{* *}, \mathrm{P}<0.01 ;{ }^{* * *}, \mathrm{P}<0.001(\mathrm{n} \geq 5)$. PLGA, poly lactic-co-glycolic acid; LDC, lidocaine.

rapidly and was eventually not detected at 4 and $5 \mathrm{~h}$, which was comparable to the control group. However, all LDCeluting coated groups demonstrated sustained LDC release. In accordance with in vitro LDC release, PLGA3000 + LDC and PLGA6000 + LDC released more LDC than PLGA $10000+\mathrm{LDC}$, and after $5 \mathrm{~h}$ intubation, the plasma LDC concentration in the PLGA6000 + LDC group was significantly higher than the PLGA $10000+$ LDC $(\mathrm{P}<0.05)$ and LDC spray groups $(\mathrm{P}<0.01)$. However, there was no significant difference between PLGA3000 + LDC and the other groups.

\section{Physiological variables}

Physiological variables including SBP, DBP, and heart rate during $5 \mathrm{~h}$ of intubation are shown in Figure 7. Among all groups, the control group presented a trend of higher SBP, DBP, and heart rate throughout the intubation period, and compared with the control and LDC-spray group, all LDC-eluting groups had a trend of lower heart rate values. Despite having similar heart rate values as those in the LDC eluting groups in the first hour of intubation, the
LDC spray group showed higher heart rate values from the second to the fifth hour and greater SBP from the third to the fifth hour than that in all LDC-eluting groups.

During the $5 \mathrm{~h}$ period of anesthesia, approximately $95 \%$ $\mathrm{SaO}_{2}$ and 35-45 mmHg $\mathrm{EtCO}_{2}$ were maintained and no significant differences in $\mathrm{SaO}_{2}$ and $\mathrm{EtCO}_{2}$ were seen among all groups (Figure S3), which revealed proper intubation depth and satisfactory respiratory function were maintained. No adverse events (e.g., dyskinesia, ataxia, restlessness, or death) were seen in any animals during the 7-day follow-up.

\section{Efficacy and safety evaluation of LDC-eluting ETTS}

Figure $8 \mathrm{~A}$ demonstrates the total consumption of supplemental propofol of each group during intubation. Compared to the control group $(113.3 \pm 6.7 \mathrm{mg})$ and LDCspray group $(76.2 \pm 4.2 \mathrm{mg})$, significantly less propofol was supplemented in the three LDC-eluting groups (44.7 $\pm 6.1 \mathrm{mg}$ in the PLGA3000 + LDC group, $34.7 \pm 6.5 \mathrm{mg}$ in the PLGA6000 + LDC group, and $55.7 \pm 6.1 \mathrm{mg}$ in the PLGA10000 + LDC group). Among the LDC-eluting groups, the PLGA $6000+$ LDC group consumed the 


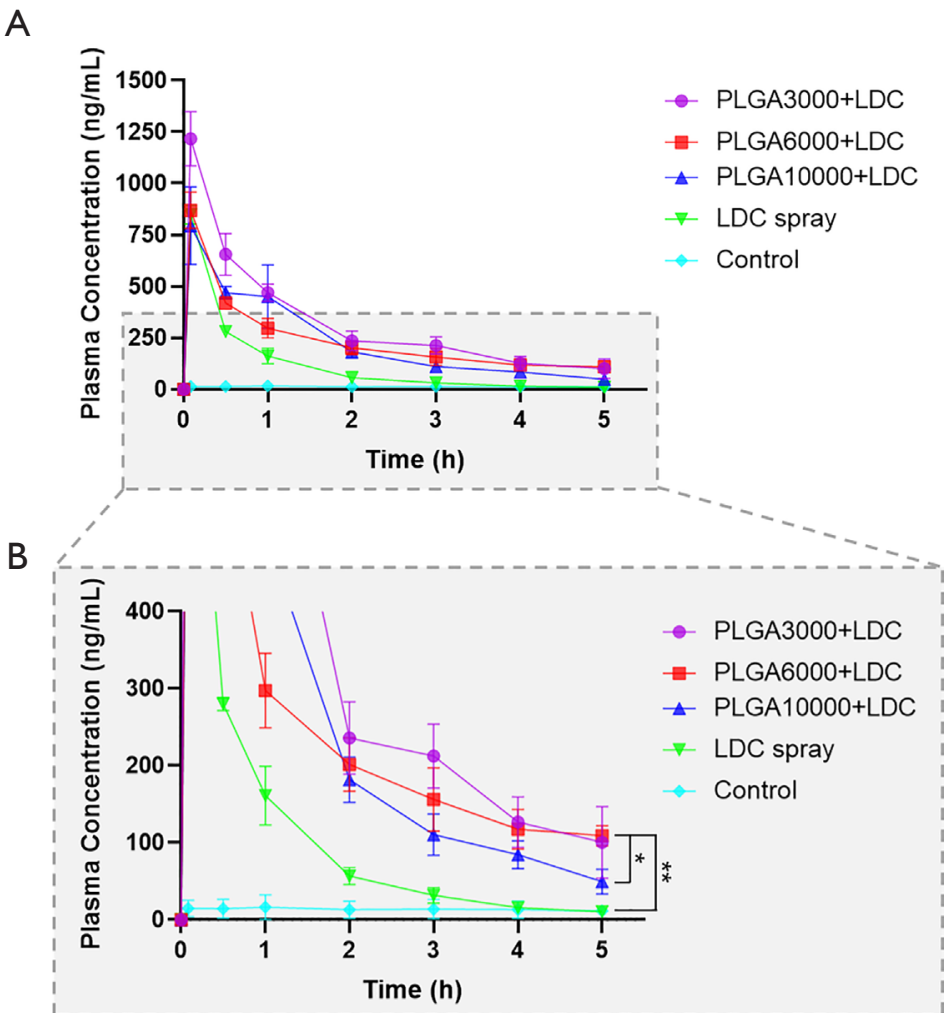

Figure 6 LDC plasma concentration-time profiles in intubated rabbits: full graph (A) and zoom in $(\mathrm{B}) .{ }^{*}, \mathrm{P}<0.05$; **, $\mathrm{P}<0.01(\mathrm{n} \geq 5)$. LDC, lidocaine.

least propofol, which was significantly lower than the PLGA10000 + LDC group $(\mathrm{P}<0.05)$. The post anesthesia tube tolerance duration in each group is shown in Figure $8 B$. There was no significant difference between control and LDC-spray, which may be because oropharyngeal spray LDC has a limited drug action duration. A longer post anesthesia tube tolerance duration in LDC-eluting ETTs $(44.9 \pm 7.7 \mathrm{~min}$ in the PLGA3000 + LDC group, 62.0 \pm $7.8 \mathrm{~min}$ in the PLGA6000 + LDC group, and $38.6 \pm 5.7 \mathrm{~min}$ in the PLGA10000 + LDC group) was in accordance with higher plasma LDC concentration compared to the control and LDC spray groups $(6.9 \pm 1.9$ and $7.5 \pm 1.4 \mathrm{~min}$, respectively).

Intubation-associated tracheal tissue damage was evaluated by measuring the mucosal edema area and mucosal thickness. Rabbits without intubation presented the minimal mucosal edema area $(6.2 \% \pm 2.2 \%$, Figure $9 \mathrm{~A}$ and $B)$ and a significantly increasing edema area was shown in the control and LDC-spray groups $(37.7 \% \pm 8.5 \%$ and $28.5 \% \pm 5.6 \%$, respectively, $\mathrm{P}<0.05$. Figure $9 A, C$ and $D)$.
As demonstrated in Figure $9 A, E$, and $F$, the use of PLGA3000 + LDC and PLGA6000 + LDC-eluting ETTs were associated with a significant reduction in the edema area compared to the control and LDCspray groups $(11.4 \% \pm 1.8 \%$ in PLGA $3000+$ LDC and $7.8 \% \pm 1.5 \%$ in PLGA $6000+$ LDC vs. $37.7 \% \pm 8.5 \%$ in control and $28.6 \% \pm 5.6 \%$ in LDC-spray; $\mathrm{P}<0.05$ and $\mathrm{P}<0.01$, respectively). Among all LDC-eluting groups, the PLGA6000 + LDC group demonstrated the least edema area and the PLGA10000 + LDC group showed the greatest edema area $(7.8 \% \pm 1.5 \%$ vs. $30.4 \% \pm 9.8 \%, \mathrm{P}<0.05$, Figure $9 A, F, G)$. Despite the different degrees of tracheal mucosal edema, no significant differences were found in the mucosal thickness among all groups (Figure 9H).

\section{Discussion}

In this study, we presented a novel method based on the PLGA polymer to deliver LDC locally with the aim of increasing the drug concentration and prolonging the 

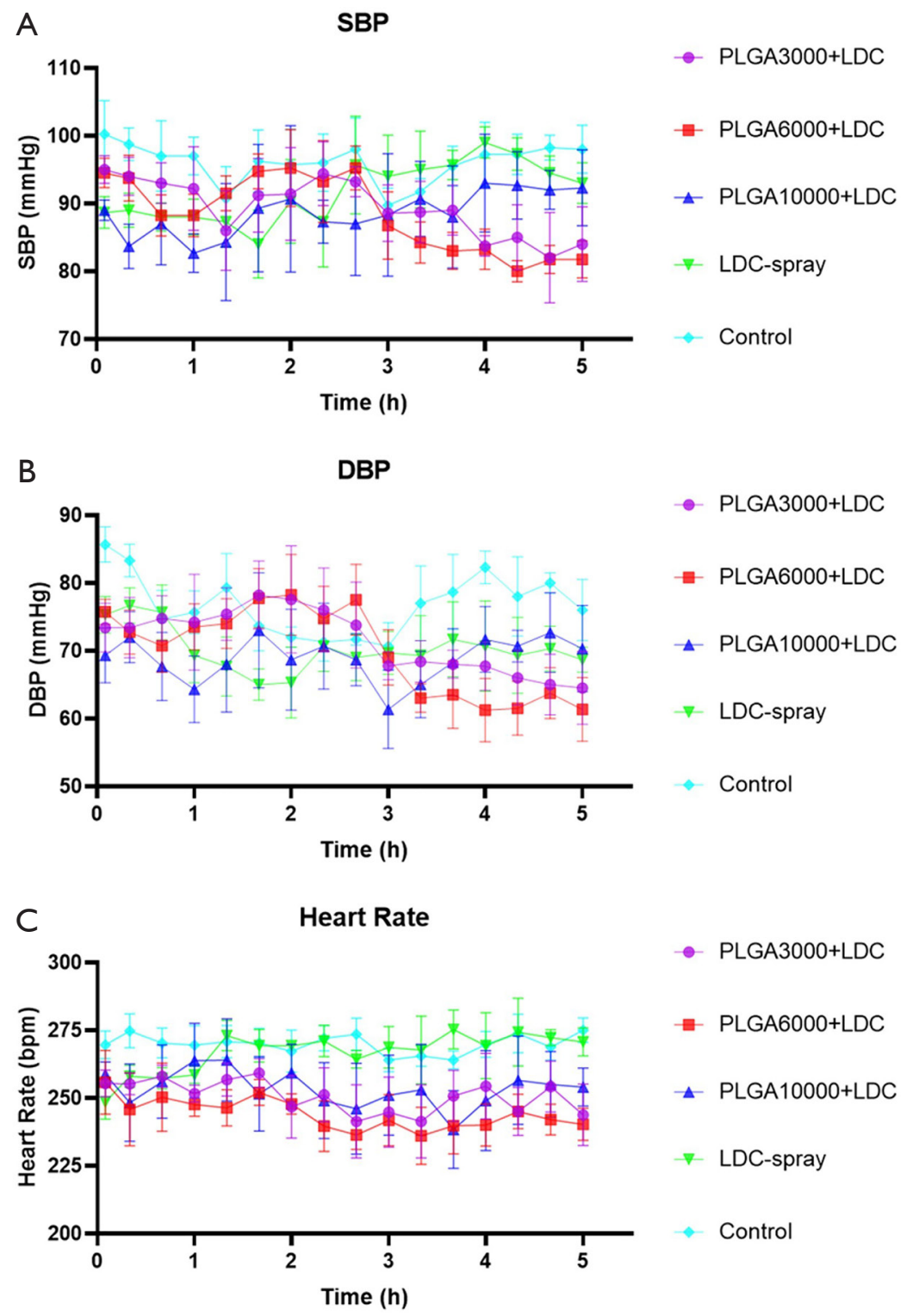

Figure 7 Physiological variables in intubated rabbits. (A) SBP, (B) DBP, and (C) heart rate in PLGA3000 + LDC, PLGA6000 + LDC, PLGA10000 + LDC, LDC-spray, and control groups at different points during $5 \mathrm{~h}$ of intubation ( $\geq 5$ ). SBP, systolic blood pressure; DBP, diastolic blood pressure; PLGA, poly lactic-co-glycolic acid; LDC, lidocaine.

anesthetic duration. Compared with uncoated tubes, the LDC-eluting tubes significantly attenuated the intubationrelated airway response, improved tube tolerance, and reduced tracheal mucosal thickness. To our knowledge, this is the first study to apply drug release techniques to deliver local anesthetic agent on the surface of ETTs.

Endotracheal intubation is widely known as a critical procedure in the management of unstable patients with COVID-19. However, coughing of patients with COVID-19 during intubation can generate aerosols which increase the risk of cross-infection (1). Herein, our LDCeluting ETT may benefit the protection of medical workers from hospital-acquired COVID-19 infection by reducing severe coughing.

The degradation rate and drug release profile of PLGA is influenced by several factors, including, but not limited 

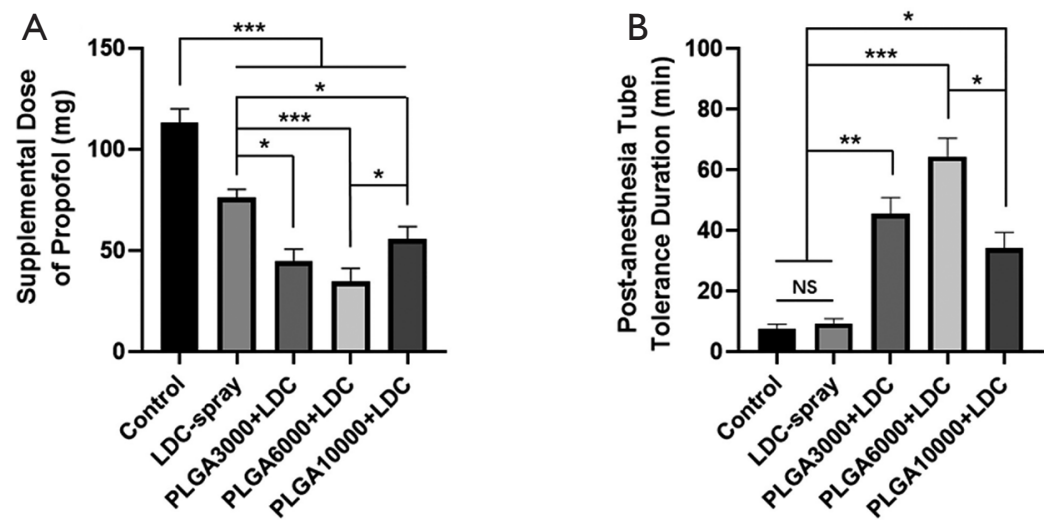

Figure 8 The enhanced anesthesia effect of LDC-eluting ETTs. (A) The supplemental dose of propofol in each group during intubation; (B) post-anesthesia tube tolerance duration. * $\mathrm{P}<0.05$; **, $\mathrm{P}<0.01$; ${ }^{* *}, \mathrm{P}<0.001$ ( $\mathrm{n} \geq 5$ ). LDC, lidocaine; ETTs, endotracheal tubes.

to, the initial MW, monomer composition ratio, drug properties, and processing method (25). The reason for selecting low MW PLGA polymers (MW: 3000-10,000; LA/GA ratio was fixed to be 50:50) in this study is based on the clinical needs for ETTs and endotracheal anesthesia. Generally, the retaining time of ETTs is from several hours to days, which requires PLGA polymers to provide rapid drug release to inhibit an intubation-related airway response and the sustainable release of a considerable amount of LDC to maintain an anesthetic effect. For a typical LDC administration for endotracheal intubation, the total dose of LDC can be as high as 200-500 $\mathrm{mg}$ for intracuff (26), or $40-50 \mathrm{mg}$ for LDC-gel lubrication $(27,28)$. However, the duration of action was less than $1.5 \mathrm{~h}$ or $30 \mathrm{~min}$, respectively. Although a larger MW PLGAs could prolong drug release for weeks, it will delay the onset time of local anesthetic and not meet the clinical needs of rapid anesthesia. Moreover, the MW of PLGA significantly influences the physical properties of PLGA copolymers as the glass transition temperature ( $\mathrm{Tg}$ ) of PLGA decreases with decreasing MW. Thus, low MW PLGA are softer than common PLGA, which was well-known to be "stiff" (29,30).

Several studies have reported biodegradable nanofiber membrane for the sustainable release of LDC significantly relieves the pain from surgical wounds or bone fractures in animal models (31-33). In our study, we set up the ratio of PLGA-to-LDC as a 1:1 mixture to facilitate higher amounts of LDC and more rapid drug release (33). The total dose of loaded LDC on the surface of size 2.5 tubes was 26.52 $0.80 \mathrm{mg}$, which was significantly higher than sprayed LDC ( $\sim 10 \mathrm{mg}$ ) for a $\sim 2.5 \mathrm{~kg}$ rabbit. Theoretically, $\sim 70 \mathrm{mg}$ LDC can be loaded on patient used tubes (e.g., size 7.0,
PLGA6000 + LDC, Table S1), and although some studies reported that more lidocaine can be instilled into the cuff of an ETT [e.g., $200 \mathrm{mg}$ for patient (26)], the concentration of diffused LDC was extremely low $(17 \mu \mathrm{g} / \mathrm{mL}$ for $200 \mathrm{mg}$ intracuff LDC in $20 \mathrm{~mL}$ distilled water after $60 \mathrm{~min}$ ) and the anesthetic effects were limited (34). The in vitro drug release in this study was $5.4 \sim 14.9 \mathrm{mg}$ LDC in the first $4 \mathrm{~h}$, which was much greater than the diffused amount of intracuff LDC and would be adequate to provide a topical anesthetic effect (Figure 5B). Clinically, lidocaine can be safely administered by bolus injection of 50-100 $\mathrm{mg}$ for ventricular arrhythmia treatment. As the dose of lidocaine on the surface of ETTs is much less than the clinically used dose, it will not cause overdose and, if needed, higher amounts of LDC can be deposited on tubes easily.

The in vitro study showed that the LDC release from each coating extended over 5 days, which meets the need of most patients receiving common surgeries under general anesthesia and endotracheal intubation. For long-term intubation, such as required in patients undergoing major surgeries or suffering from respiratory failure, additional replacement of LDC-eluting ETT can easily be performed to achieve an additional 5 days of topical anesthetic effect, which is also recommended for prolonged mechanical ventilation (>10-14 days) (35-37). The in vitro study was translated to sustained release onto the surface of the trachea and into the plasma of our rabbit model. As LDCspray is the most used local anesthetic approach, we set up one LDC-spray group in this study to simulate LDC use in clinical practice, and in vivo plasma drug concentration testing revealed that LDC-spray lasted less than $3 \mathrm{~h}$. In contrast, LDC-eluting coatings allowed a longer duration 

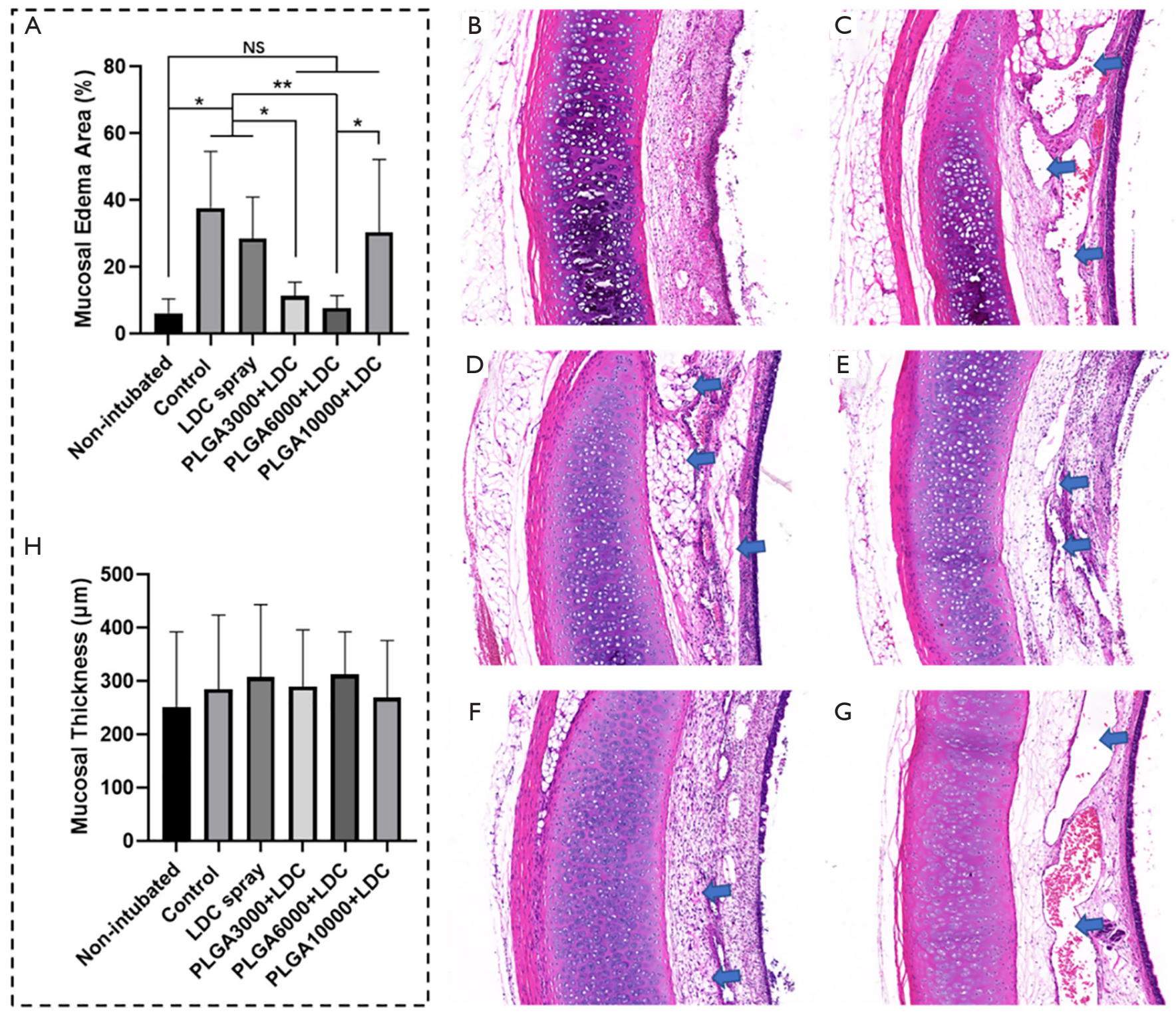

Figure 9 Representative HE stained sections of trachea tissue $(\times 100)$. (A) Cross-section area of tracheal mucosal edema, (B) non-intubated, (C) control (uncoated tube), (D) LDC spray, (E) PLGA3000 + LDC, (F) PLGA6000 + LDC, (G) PLGA10000 + LDC. Blue arrows indicate

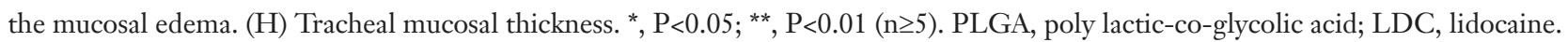

of LDC release (at least $5 \mathrm{~h}$ ), and this trend was more significant in the PLGA6000 + LDC group which exhibited higher plasma drug concentration than in the PLGA10000 + LDC group. Additionally, all the LDC-eluting coatings manifested the characteristics of "eruptive" drug release, which conformed to the requirement of rapid anesthesia for avoiding an airway response in the intubation procedure (Figure 6).

Corresponding to higher drug concentration and longer effective duration, the animals that received LDC-eluting tube intubation had dramatically less propofol consumption and significantly longer post-anesthesia tube tolerance duration (Figure 8). In addition, records of physiological variables revealed that the three LDC-eluting groups experienced more stable hemodynamic parameters (HR, SAP, and DAP) compared to the control and LDC spray groups (Figure 7). These results may be attributed to the superior LDC coating-related anesthetic effects. 
Clinically, tracheal damage and tissue edema are important factors resulting in intubation-related complications. Histological assessment in this study demonstrated there were no significant differences in mucosal thickness in all groups (Figure 9H). Interestingly, less mucosal edema area was found in the PLGA3000 + LDC and PLGA6000 + LDC groups compared to the control, LDC-spray, and PLGA10000 + LDC groups (Figure 9A). The mechanism underlying the reduced edema area in the PLGA3000 + LDC and PLGA6000 + LDC groups may be related to less motion from the animals due to the superior anesthesia effects. Despite a similar anesthesia effect to the other LDC-eluting groups, the PLGA10000 + LDC group had a greater edema area, which might be due to the material features of PLGA10000. The morphological assessment from SEM revealed that PLGA10000 + LDC presented a more irregular surface (Figure $4 D$ ), which might result in an adverse airway response and cause mucosal edema. Of all the LDC-coated ETT groups, the PLGA6000 + LDC group showed the most uniform coating, which may be associated with the physical property of PLGA6000, which is less 'sticky' than PLGA3000 and not as 'crisp' as PLGA10000 (Figure 4). Therefore, the development of soft polymer coatings with self-lubricating and drug-releasing functions could be a direction for future research. Moreover, the co-delivery of local anesthetics and anti-inflammatories from ETTs is also worthy of further study.

\section{Conclusions}

An LDC-eluting coating based on PLGA on the surface of ETT provides rapid and sustained drug release, reduces tracheal tissue damage, and improves intubation tolerance, and due to its appropriate material features, PLGA6000 + LDC is suitable to serve as an LDC delivery coating. This study provides an innovative attempt and presents a potential treatment approach for the care of patients undergoing intubation.

\section{Acknowledgments}

Funding: This work was supported by grants from the Natural Science Foundation of China [No. 31800795], Sichuan Science and Technology Program [No. 2021JDRC0160], Fundamental Research Funds for the Central Universities [No. 2682019CX72], Research program of Health Commission of Sichuan Province [17PJ221] and Youth Funds of Sichuan Provincial People's Hospital [2014QN16].

\section{Footnote}

Reporting Checklist: The authors have completed the ARRIVE reporting checklist. Available at http://dx.doi. org/10.21037/atm-21-1930

Data Sharing Statement: Available at http://dx.doi. org/10.21037/atm-21-1930

Conflicts of Interest: All authors have completed the ICMJE uniform disclosure form (available at http://dx.doi. org/10.21037/atm-21-1930). Dr. Jing Lu and Dr. Lei Lu report that patent application is pending with the number CN111035815. The other authors have no conflicts of interest to declare.

Ethical Statement: The authors are accountable for all aspects of the work in ensuring that questions related to the accuracy or integrity of any part of the work are appropriately investigated and resolved. This study was approved by the West China Hospital of Sichuan University Biomedical Research Ethics Committee and animals were treated in accordance with the Guide for the Care and Use of Laboratory Animal of the US National Institutes of Health (NIH).

Open Access Statement: This is an Open Access article distributed in accordance with the Creative Commons Attribution-NonCommercial-NoDerivs 4.0 International License (CC BY-NC-ND 4.0), which permits the noncommercial replication and distribution of the article with the strict proviso that no changes or edits are made and the original work is properly cited (including links to both the formal publication through the relevant DOI and the license). See: https://creativecommons.org/licenses/by-nc-nd/4.0/.

\section{References}

1. Meng L, Qiu H, Wan L, et al. Intubation and Ventilation amid the COVID-19 OutbreakWuhan's Experience. Anesthesiology 2020;132:1317-32.

2. Aminnejad R, Salimi A, Saeidi M. Lidocaine during intubation and extubation in patients with coronavirus 
disease (COVID-19). Can J Anaesth 2020;67:759.

3. Hung NK, Wu CT, Chan SM, et al. Effect on postoperative sore throat of spraying the endotracheal tube cuff with benzydamine hydrochloride, 10\% lidocaine, and 2\% lidocaine. Anesth Analg 2010;111:882-6.

4. Beebe DS. editor. Complications of tracheal intubation. Seminars in Anesthesia, Perioperative Medicine and Pain. Elsevier, 2001.

5. Tadié JM, Behm E, Lecuyer L, et al. Post-intubation laryngeal injuries and extubation failure: a fiberoptic endoscopic study. Intensive Care Med 2010;36:991-8.

6. Lev R, Rosen P. Prophylactic lidocaine use preintubation: a review. J Emerg Med 1994;12:499-506.

7. Hashemian AM, Doloo HZM, Saadatfar M, et al. Effects of intravenous administration of fentanyl and lidocaine on hemodynamic responses following endotracheal intubation. Am J Emerg Med 2018;36:197-201.

8. Jung JY. Airway management of patients with traumatic brain injury/C-spine injury. Korean J Anesthesiol 2015;68:213.

9. Klemola UM, Saarnivaara L, Yrjölä H. Post-operative sore throat: effect of lignocaine jelly and spray with endotracheal intubation. Eur J Anaesthesiol 1988;5:391-9.

10. Tung A, Fergusson NA, Ng N, et al. Medications to reduce emergence coughing after general anaesthesia with tracheal intubation: a systematic review and network metaanalysis. Br J Anaesth 2020. [Epub ahead of print]. doi: 10.1016/j.bja.2019.12.041.

11. Lv L, Lei Y, Xun L, et al. Effectiveness of lidocaine/ prilocaine cream on cardiovascular reactions from endotracheal intubation and cough events during recovery period of older patients under general anesthesia: prospective, randomized placebo-controlled study. BMC Geriatr 2020;20:157.

12. Jee D, Park SY. Lidocaine sprayed down the endotracheal tube attenuates the airway-circulatory reflexes by local anesthesia during emergence and extubation. Anesth Analg 2003;96:293-7.

13. Estebe JP, Dollo G, Le Corre P, et al. Alkalinization of intracuff lidocaine improves endotracheal tube-induced emergence phenomena. Anesth Analg 2002;94:227-30.

14. Pirlich N, Lohse JA, Noppens RR. Topical airway anesthesia for awake-endoscopic intubation using the spray-as-you-go technique with high oxygen flow. J Vis Exp 2017;(119):55116.

15. Groeben H, Silvanus MT, Beste M, et al. Both intravenous and inhaled lidocaine attenuate reflex bronchoconstriction but at different plasma concentrations. Am J Respir Crit
Care Med 1999;159:530-5.

16. Abu Ammar A, Gruber M, Martin P, et al. Local delivery of mometasone furoate from an eluting endotracheal tube. J Control Release 2018;272:54-61.

17. Jones DS, McCoy CP, Andrews GP, et al. Hydrogel antimicrobial capture coatings for endotracheal tubes: A pharmaceutical strategy designed to prevent ventilatorassociated pneumonia. Mol Pharm 2015;12:2928-36.

18. Hashemi MM, Rovig J, Bateman J, et al. Preclinical testing of a broad-spectrum antimicrobial endotracheal tube coated with an innate immune synthetic mimic. J Antimicrob Chemother 2018;73:143-50.

19. Piccolo R, Bonaa KH, Efthimiou O, et al. Drug-eluting or bare-metal stents for percutaneous coronary intervention: a systematic review and individual patient data meta-analysis of randomised clinical trials. Lancet 2019;393:2503-10.

20. Eisenberg MJ, Konnyu KJ. Review of randomized clinical trials of drug-eluting stents for the prevention of in-stent restenosis. Am J Cardiol 2006;98:375-82.

21. Günday Türeli N, Torge A, Juntke J, et al. Ciprofloxacinloaded PLGA nanoparticles against cystic fibrosis P. aeruginosa lung infections. Eur J Pharm Biopharm 2017;117:363-71.

22. Kapoor DN, Bhatia A, Kaur R, et al. PLGA: a unique polymer for drug delivery. Ther Deliv 2015;6:41-58.

23. Makadia HK, Siegel SJ. Poly lactic-co-glycolic acid (PLGA) as biodegradable controlled drug delivery carrier. Polymers 2011;3:1377-97.

24. Vajragupta O, La-Ong S. Synthesis and skin permeation study of lidocaine organic salts. Drug Dev Ind Pharm 1994;20:2671-84.

25. Xu Y, Kim CS, Saylor DM, et al. Polymer degradation and drug delivery in PLGA-based drug-polymer applications: A review of experiments and theories. J Biomed Mater Res B Appl Biomater 2017;105:1692-716.

26. Hirota W, Kobayashi W, Igarashi K, et al. Lidocaine added to a tracheostomy tube cuff reduces tube discomfort. Can J Anaesth 2000;47:412.

27. Sumathi PA, Shenoy T, Ambareesha M, et al. Controlled comparison between betamethasone gel and lidocaine jelly applied over tracheal tube to reduce postoperative sore throat, cough, and hoarseness of voice. Br J Anaesth 2008;100:215-8.

28. Thapa P, Shrestha RR, Shrestha S, et al. Betamethasone gel compared with lidocaine jelly to reduce tracheal tube related postoperative airway symptoms: a randomized controlled trial. BMC Res Notes 2017;10:361.

29. Wang N, Wu XS, Li C, et al. Synthesis, characterization, 
biodegradation, and drug delivery application of biodegradable lactic/glycolic acid polymers: I. Synthesis and characterization. J Biomater Sci Polym Ed 2000;11:301-18.

30. Pitt CG, Gu ZW. Modification of the rates of chain cleavage of poly ( $\epsilon$-caprolactone) and related polyesters in the solid state. J Control Release 1987;4:283-92.

31. Liu KS, Chen WH, Lee CH, et al. Extended pain relief achieved by analgesic-eluting biodegradable nanofibers in the Nuss procedure: In vitro and in vivo studies. Int J Nanomedicine 2018;13:8355.

32. Kao CW, Lee D, Wu MH, et al. Lidocaine/ketorolacloaded biodegradable nanofibrous anti-adhesive membranes that offer sustained pain relief for surgical wounds. Int J Nanomedicine 2017;12:5893.

33. Yu YH, Hsu YH, Chou YC, et al. Sustained relief of pain from osteosynthesis surgery of rib fracture by using biodegradable lidocaine-eluting nanofibrous membranes. Nanomedicine 2016;12:1785-93.

Cite this article as: Lu J, Tian W, Cui L, Cai B, Zhang T, Huang N, Lu L, Zhu T. Lidocaine-eluting endotracheal tube effectively attenuates intubation related airway response. Ann Transl Med 202 1;9(10):871. doi: 10.21037/atm-21-1930
34. Behzadi M, Hajimohamadi F, Alagha AE, et al. Endotracheal tube cuff lidocaine is not superior to intravenous lidocaine in short pediatric surgeries. Int J Pediatr Otorhinolaryngol 2010;74:486-8.

35. Wang R, Pan C, Wang X, et al. The impact of tracheotomy timing in critically ill patients undergoing mechanical ventilation: A meta-analysis of randomized controlled clinical trials with trial sequential analysis. Heart Lung 2019;48:46-54.

36. Wakeham MK, Kuhn EM, Lee KJ, et al. Use of tracheostomy in the PICU among patients requiring prolonged mechanical ventilation. Intensive Care Med 2014;40:863-70.

37. Cheung NH, Napolitano LM. Tracheostomy: Epidemiology, Indications, Timing, Technique, and Outcomes Discussion. Respir Care 2014;59:895-915; discussion 916-9.

(English Language Editor: B. Draper) 


\section{Supplementary}

Table S1 The loaded dose of LDC-eluting coatings on PVC discs and size 2.5 endotracheal tubes

\begin{tabular}{|c|c|c|c|c|}
\hline \multirow{2}{*}{ Coating } & \multicolumn{2}{|c|}{ PVC discs } & \multicolumn{2}{|c|}{ Endotracheal tubes } \\
\hline & Dose per area $\left(\mathrm{mg} / \mathrm{cm}^{2}\right)$ & Loading dose ${ }^{\star *}(\mathrm{mg})$ & Dose per area* $\left(\mathrm{mg} / \mathrm{cm}^{2}\right)$ & Loading dose ${ }^{\star \star}(\mathrm{mg})$ \\
\hline PLGA3000 + LDC & $2.47 \pm 0.11$ & $25.63 \pm 1.18$ & $2.49 \pm 0.09$ & $25.32 \pm 0.70$ \\
\hline PLGA6000 + LDC & $2.44 \pm 0.06$ & $25.31 \pm 0.63$ & $2.58 \pm 0.09$ & $26.52 \pm 0.80$ \\
\hline PLGA10000 + LDC & $2.35 \pm 0.09$ & $24.36 \pm 0.97$ & $2.45 \pm 0.04$ & $25.78 \pm 0.56$ \\
\hline
\end{tabular}

*: Dose per area $=\left(\right.$ Loading dose/coating area); ${ }^{* *}$ : Loading dose $=$ coating weight/2; coating area was estimated as: $0.33 \mathrm{~cm} \times 3.14 \times$ $10 \mathrm{~cm}=10.36 \mathrm{~cm}^{2}$. Data are represented as mean $\pm \mathrm{SEM}, \mathrm{n} \geq 5$.

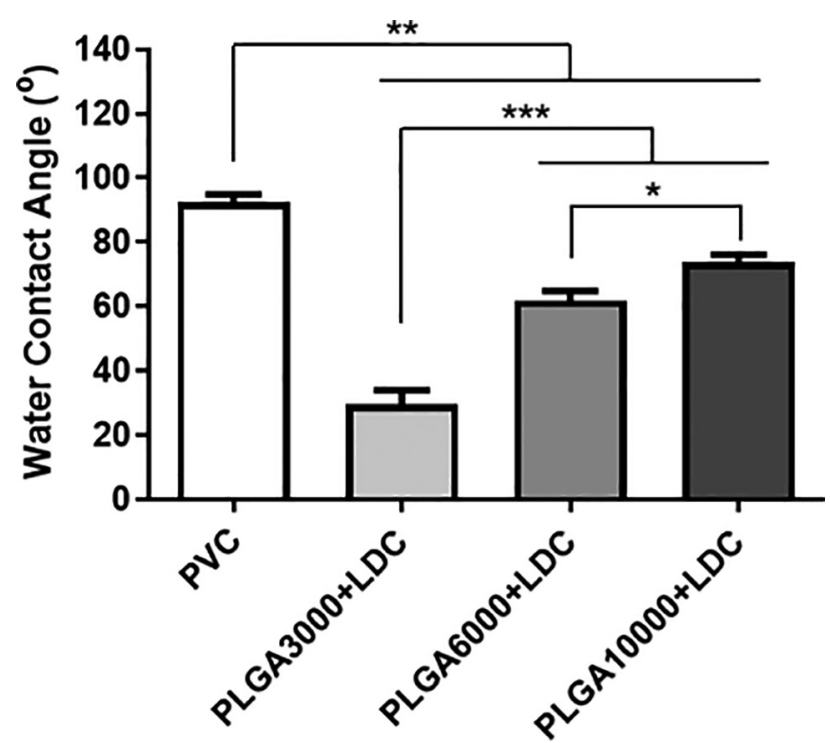

Figure S1 Water contact angles of the PVC, PLGA3000 + LDC, PLGA6000 + LDC, and PLGA10000 + LDC surfaces. Data are represented as mean $\pm \mathrm{SEM}, \mathrm{n} \geq 5$. The significance was evaluated for ${ }^{*} \mathrm{P}<0.05,{ }^{* *} \mathrm{P}<0.01,{ }^{* * *} \mathrm{P}<0.001$. 

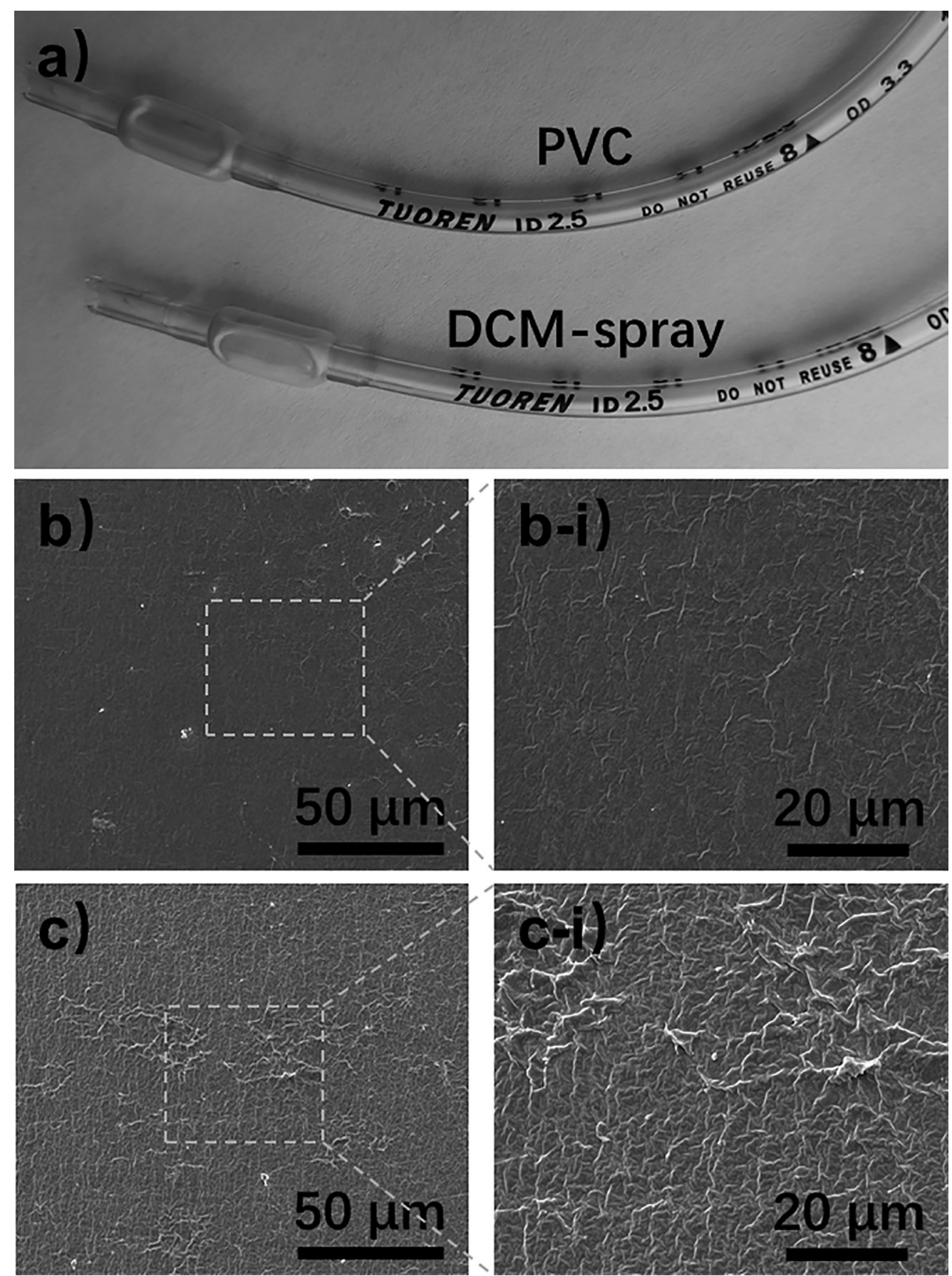

Figure S2 Images and SEM morphology of uncoated PVC tube and tube with DCM spraying for $15 \mathrm{~s}$. Both tubes remain transparent (A). Compared with uncoated PVC tube (B), only minor swelling due to the DCM can be observed under SEM (C). The representative area of the highest degree of swelling due to the DCM was observed (C-i). 
a)

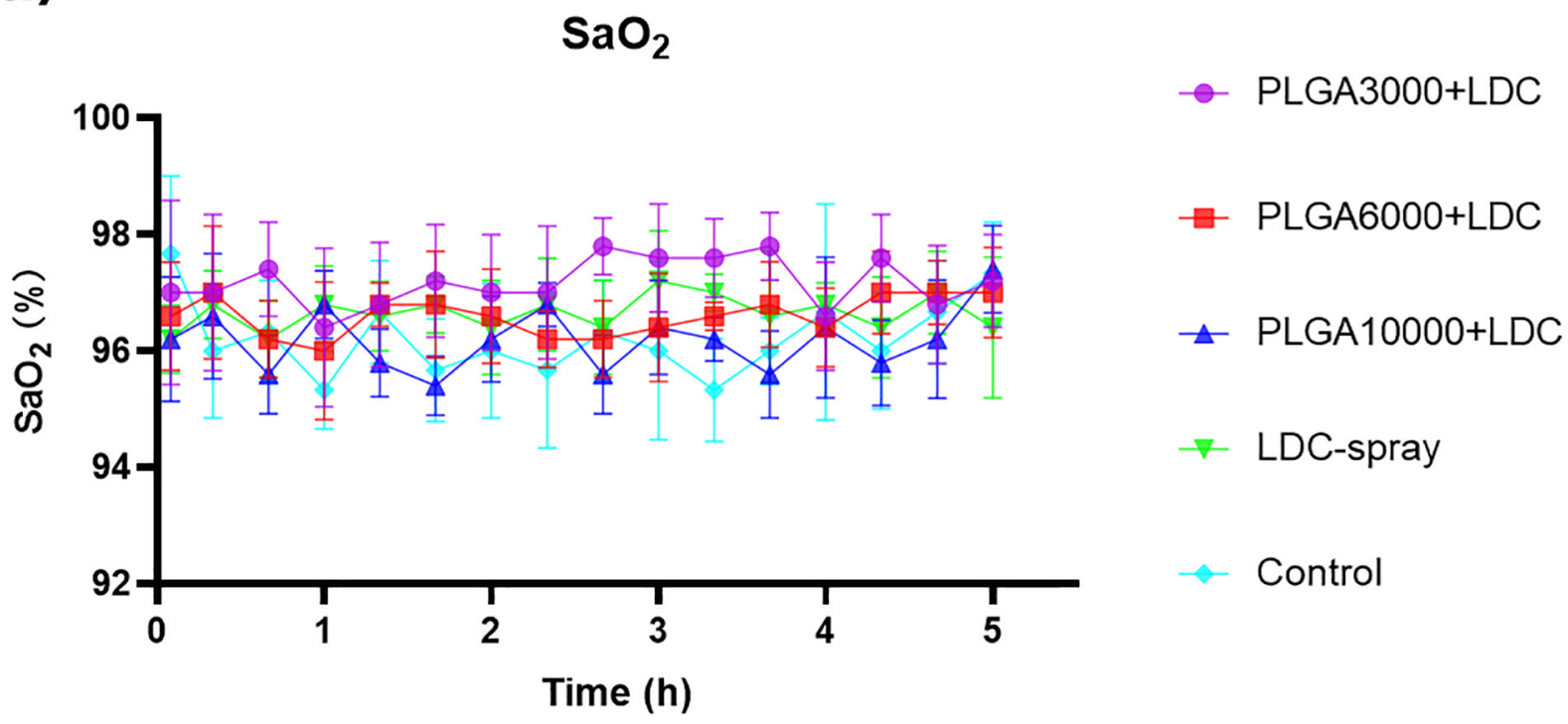

b)

$\mathrm{EtCO}_{2}$

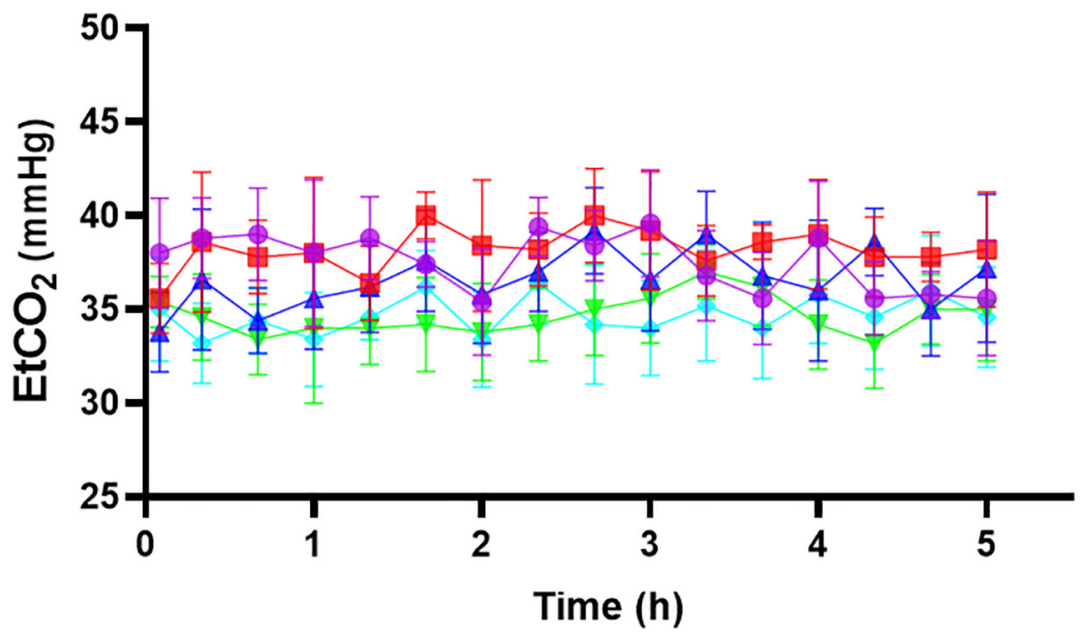

- PLGA3000+LDC

- PLGA6000+LDC

^ PLGA10000+LDC

7 LDC-spray

$\rightarrow$ Control

Figure S3 $\mathrm{SaO} 2$ and EtCO2 variables in different groups during 5 h of intubation. (A) $\mathrm{SaO} 2$; (B) EtCO2. Data are represented as mean \pm $\mathrm{SEM}, \mathrm{n} \geq 5$. 